\title{
\begin{tabular}{l|l} 
Mitraries & DSpace@MIT
\end{tabular}
}

\author{
MIT Open Access Articles
}

Effects of Transient Heat Transfer on Compressor Stability

The MIT Faculty has made this article openly available. Please share how this access benefits you. Your story matters.

Citation: Kiss, A. and Z. Spakovszky. "Effects of Transient Heat Transfer on Compressor Stability." Journal of Turbomachinery 140, 12 (December 2019): 121003 (c) 2019 ASME

As Published: http://dx.doi.org/10.1115/1.4041290

Publisher: American Society of Mechanical Engineers (ASME)

Persistent URL: https://hdl.handle.net/1721.1/123436

Version: Final published version: final published article, as it appeared in a journal, conference proceedings, or other formally published context

Terms of Use: Article is made available in accordance with the publisher's policy and may be subject to US copyright law. Please refer to the publisher's site for terms of use. 


\section{Effects of Transient Heat Transfer on Compressor Stability}

\author{
A. Kiss ${ }^{1}$ \\ Gas Turbine Laboratory, \\ Massachusetts Institute of Technology, \\ 77 Massachusetts Avenue, \\ Cambridge, MA 02139 \\ e-mail: akiss@mit.edu

\section{Z. Spakovszky} \\ Gas Turbine Laboratory, \\ Massachusetts Institute of Technology, \\ 77 Massachusetts Avenue, \\ Cambridge, MA 02139 \\ e-mail: zolti@mit.edu
}

The effects of heat transfer between the compressor structure and the primary gas path flow on compressor stability are investigated during hot engine re-acceleration transients. A mean line analysis of an advanced, high-pressure ratio compressor is extended to include the effects of heat transfer on both stage matching and blade row flow angle deviation. A lumped capacitance model is used to compute the heat transfer of the compressor blades, hub, and casing to the primary gas path. The inputs to the compressor model with heat transfer are based on a combination of full engine data, compressor test rig measurements, and detailed heat transfer computations. Nonadiabatic transient calculations show a 8.0 point reduction in stall margin from the adiabatic case, with heat transfer predominantly altering the transient stall line. 3.4 points of the total stall margin reduction are attributed to the effect of heat transfer on blade row deviation, with the remainder attributed to stage rematching. Heat transfer increases loading in the front stages and destabilizes the front block. Sensitivity studies show a strong dependence of stall margin to heat transfer magnitude and flow angle deviation at low speed, due to the effects of compressibility. Computations for the same transient using current cycle models with bulk heat transfer effects only capture 1.2 points of the 8.0 point stall margin reduction. Based on this new capability, opportunities exist early in the design process to address potential stability issues due to transient heat transfer. [DOI: 10.1115/1.4041290]

\section{Introduction}

During an engine transient, convective heat transfer occurs between exposed surfaces of the compressor and the main gas path fluid due to differences in the characteristic time scales of the gas path fluid and metal temperatures. The flow through the compressor can be considered quasi-steady as the reduced frequency, based on the flow through time and the rotor acceleration time constant, ${ }^{2}$ is typically on the order of $10^{-3}$. The time scale of the main gas path fluid temperature is therefore governed by rotor speed. Component temperatures, however, lag behind the main gas path fluid temperature due to thermal inertia, and the resultant temperature difference drives the heat transfer.

Transient heat transfer impacts compressor stability in three different ways. First, changing component temperatures leads to thermal growth of the rotors and casing, changing the tip clearances. Second, heat transfer from the gas path alters the compressor stage matching, reducing stability, and shifting the stall line toward the operating line. The altered stage matching also shifts the transient operating line up, which further reduces stall margin, ${ }^{3}$ however, it will be shown that this effect is less significant. Finally, heat transfer between the blade surface and the gas path alters the blade boundary layer development, changing the blade row total pressure loss and deviation, further impacting stage matching and stability.

Much of the literature has focused on investigating changes in tip clearances due to heat transfer and the associated impact on compressor stability (e.g., see Refs. [1] and [2]) and information on the impact of heat transfer to the main gas path is limited. Maccallum and Grant [3] simulated the effects of heat transfer during

\footnotetext{
${ }^{1}$ Corresponding author.

${ }^{2}$ The rotor acceleration time constant is governed by the rotor inertia and is typically on the order of seconds.

${ }^{3}$ In this paper, stall margin is defined using the common industry definition: $\mathrm{SM}=\left(\mathrm{PR}_{\mathrm{stall}}-\mathrm{PR}_{\mathrm{op}}\right) / \mathrm{PR}_{\mathrm{op}}$, where $\mathrm{PR}_{\mathrm{op}}$ is the pressure ratio at the operating point and $\mathrm{PR}_{\text {stall }}$ is the pressure ratio at stall for a given inlet corrected mass flow.

Contributed by the International Gas Turbine Institute (IGTI) of ASME for publication in the Journal of Turbomachinery. Manuscript received August 2, 2018; final manuscript received August 21, 2018; published online October 15, 2018. Editor: Kenneth Hall.
}

a high altitude deceleration using a boundary layer model and found the change in deviation to be approximately 1 deg for heat transfer rates approximately half that in the current study. Incorporating this into a mean line model, heat transfer resulted in a 12.2 point reduction in stall margin for a 12 stage compressor with a pressure ratio of $5.60 \%$ of the total loss was attributed to deviation effects and $40 \%$ due to stage matching. Crawford and Burwell [4] later computed the heat transfer for several "Bodie" transient experiments and found that the heat transfer was greater for transients in which the compressor stalled. Recently, Lou et al. [5] found heat transfer responsible for reduced stall margin during hot deceleration transients in a high-speed centrifugal compressor.

\section{Scope of Paper}

While there is evidence of detrimental heat transfer effects on compressor stability, there is a lack of capability to characterize these effects from first principles. As a result, empirical models are often used during the design process. This paper rigorously assesses the effects of transient heat transfer on compressor stability by addressing the following objectives:

(1) Quantify stall margin loss due to transient heat transfer based on first-principles.

(2) Quantify the relative contribution of stage matching and changes in blade boundary layer development to the total stall margin loss.

(3) Characterize the underlying mechanisms that govern stall margin loss due to transient heat transfer.

(4) Assess the sensitivity of stall margin loss to heat transfer effects.

The paper is organized as follows: a mean line model with heat transfer effects is first introduced and a lumped capacitance model is derived to estimate the component heat transfer during an engine transient. It is shown that stage mismatching is the key contributor to stall margin loss. A detailed stage matching analysis, together with a study of the impact of heat transfer at different axial locations, follows and demonstrates that increased front stage loading leads to instability. An assessment of stall margin 
loss to heat transfer magnitude shows the stage matching to be particularly sensitive at low speed, where the compressibility effects due to heat transfer become significant. Finally, the capability of the modified mean line is compared to conventional zerodimensional modeling of the compressor map, revealing significant potential to improve the compressor design process.

\section{Technical Approach}

Mean Line Model. A mean line model of a core compressor was modified to incorporate the effects of heat transfer. A detailed description of the implementation can be found in Ref. [6]. The object-oriented turbomachinery analysis code (OTAC) is implemented in the numerical propulsion system simulation (NPSS) framework $[7,8]$. Utilizing OTAC allowed the mean line model to be coupled with a combustor model in NPSS to capture compressor-turbine matching. Blade row inputs such as blade geometry, loss and deviation characteristics, and flow path blockage were derived from detailed computations of an eight stage, high pressure ratio core compressor of advanced design. As the reduced frequency (based on flow-through time and the rotor acceleration time constant) was much less than unity, simulations of transient events were performed in a quasi-steady manner using the NPSS steady solver. The nozzle guide vanes of the high pressure turbine were assumed to be choked throughout the transient. Transient fuel flow and variable geometry schedules were also included. The core compressor inlet stagnation pressure and temperature and the corrected shaft speed were imposed as a function of time and derived from the industry sponsor's engine system model. The adiabatic model performance, both steady-state and transient, agree within $2 \%$ of data from the engine system model [6]. The computed baseline adiabatic operating line for a Bodie transient and adiabatic compressor map is given in Fig. 1.

The adiabatic mean line code was extended to include the effects of heat transfer on blade loss and flow angle deviation. Shah [9] found that changes in blade stagnation pressure loss due to heat transfer can be appropriately modeled by isobaric, constant area channel flow with heat transfer (Rayleigh flow). It was also found that flow angle deviation $\delta$ varied linearly both with heat transfer rate and blade relative Mach numbers. These two correlations were implemented in the mean line model according to

$$
\begin{aligned}
& \frac{\Delta p_{t, \mathrm{HX}}}{p_{t, i}} \approx-\frac{\gamma M_{\mathrm{rel}, i}^{2}}{2} q^{*} \quad\left|q^{*}\right| \ll 1 \\
& \Delta \delta=\frac{q^{*}}{0.001} \zeta \begin{cases}\zeta=0.1 \mathrm{deg} & \text { for } M_{\mathrm{rel}, i}=0.4 \\
\zeta=0.25 \mathrm{deg} & \text { for } M_{\mathrm{rel}, i}=0.8\end{cases}
\end{aligned}
$$

where $q^{*}$ is the heat transfer rate nondimensionalized by the blade inlet stagnation enthalpy inflow rate. To quantify the relative importance of stage rematching and deviation effects, the

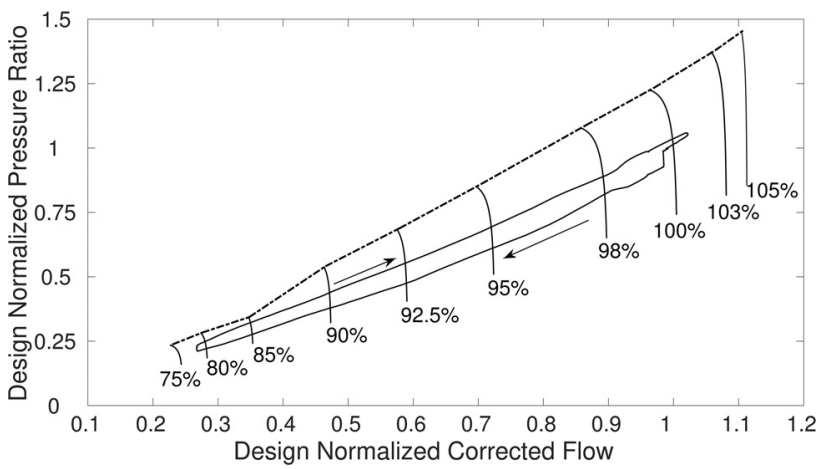

Fig. 1 Baseline adiabatic operating line and compressor map for Bodie transient from mean line model deviation correlation parameter $\zeta$ can be set to zero, removing the effects of heat transfer on flow angle deviation. The unsteady, dimensional heat transfer rate $\dot{Q}(\tau)$ for each blade row was an input to the mean line model and was estimated using a lumped capacitance model.

Lumped Capacitance Model. A lumped capacitance model was developed to estimate representative heat transfer rates from the exposed surfaces to the main gas path. For each blade row, the blade surface, casing, hub, and rotor disk bulk temperatures were modeled. The temperature of the cavity in which the disks reside was also modeled and the cavity air was fed by an interstage bleed. The modeled heat transfer mechanisms and component temperatures are represented by a thermal network, summarized for a single stage in Fig. 2. The dominant mechanism is convection from the casing, hub, and blade surfaces to the main gas path. Geometrical and material parameters for each blade row were provided by the industry sponsor. Component convective heat transfer coefficients with the main gas path for each blade row were derived from high fidelity computations at several corrected speeds.

Also modeled are secondary heat transfer mechanisms such as convection between the rotor disk surface and the cavity (windage), radial conduction between the disk and the hub surface, and

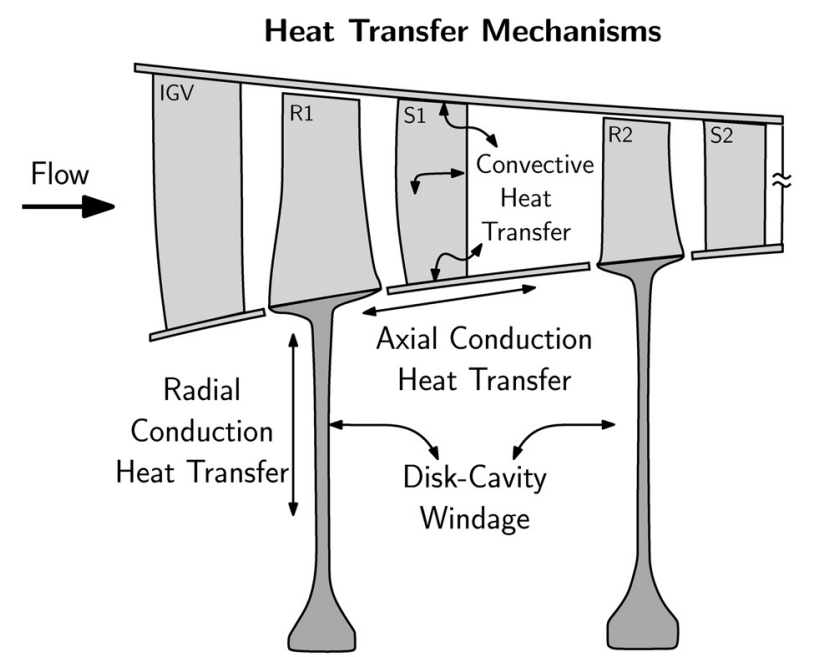

Model Representation

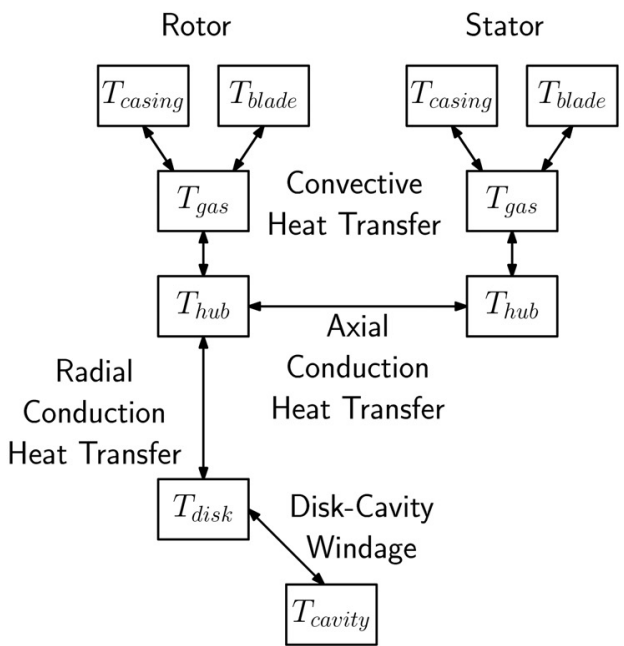

Fig. 2 Modeled heat transfer mechanisms and thermal network representation used to estimate representative heat transfer 


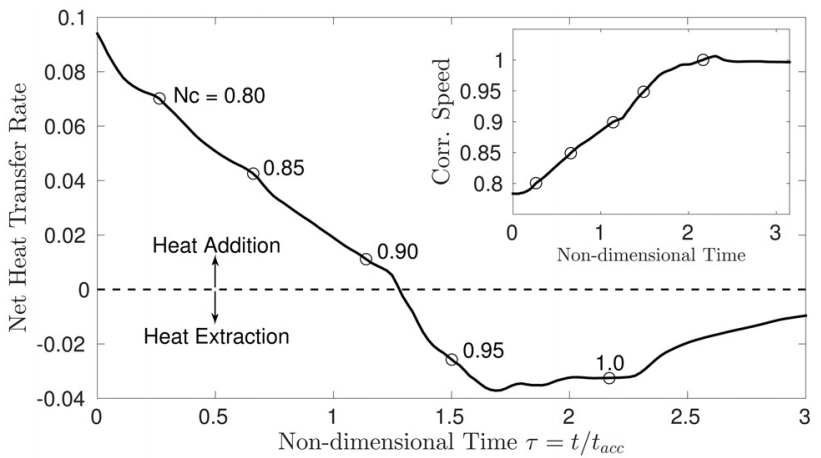

Fig. 3 Transient net heat transfer rate during re-acceleration portion of a Bodie with maximum heat addition at initial reacceleration

axial conduction between different hub sections. Farthing et al. [10] found that windage Nusselt numbers correlated well with a Reynolds number based on disk rim speed and radius. For each instant in time during the transient, the windage Nusselt number was recomputed based on the correlation in Ref. [10] to determine the windage convective heat transfer coefficient.

To estimate the unsteady heat transfer, the adiabatic flow field ${ }^{4}$ was first computed for an adiabatic Bodie transient. The component metal temperatures in the model were initialized using the gas path temperatures at the steady-state operating point at the beginning of the transient. The model was then marched forward in time with the gas path temperatures from the adiabatic flow field serving as an unsteady boundary condition. The transient heat transfer rate, an input to the nonadiabatic mean line model, and updated component temperatures were computed at each instant in time. The lumped capacitance model was validated with high fidelity computations for a snap acceleration transient, proving its ability to estimate representative heat transfer rates for transient events.

The net heat transfer rate for the re-acceleration portion of the Bodie transient is a function of time nondimensionalized by the acceleration time constant, as shown in Fig. 3. The maximum heat addition occurs at the beginning of re-acceleration when the metal component temperatures are still high due to their greater thermal inertia, and the gas path temperatures are low. As the transient progresses, the heat addition decreases as the gas path temperatures increase, with a period of heat extraction occurring at high speed. As will be shown, the period of heat addition at low speed will be the most critical time of the transient during which the greatest stall margin loss occurs.

Stall Detection Criterion. To determine the compressor stall points, it is necessary to define a stall criterion within the framework of the mean line model. Generally, there are two routes to rotating stall: modal-type and spike-type stall inception [11]. Spike-type stall inception has been shown to be the result of a blade exceeding a critical incidence angle and the resultant separation and shedding of leading-edge vorticity [12]. As blade loading is a direct function of the incidence angle, and determining the critical incidence angle with three-dimensional CFD was beyond the scope of this work, a stall criterion to capture spike-type stall was based on the Lieblein diffusion factor [13]. If an operating point resulted in a blade row exceeding the critical diffusion factor (typically 0.6), the compressor was considered to have stalled due to spike-type stall. The critical diffusion factor was determined by examining the diffusion factor of each blade row at the known adiabatic stall line.

${ }^{4}$ Flow field is here used in the mean line sense, i.e., flow velocity, flow angle, pressure, and temperature at each blade row inlet and outlet.
The concept of disturbance power generation was used to capture modal-type stall inception. Rotating stall and surge are the natural oscillations of the system initiated by the growth of long wavelength (radius scale) prestall waves. Disturbance power is the energy contained in the eigenmodes of the compression system which describe these prestall waves [14]. Each blade row produces positive or negative disturbance power, corresponding to negative or positive damping, respectively. The stability limit is the point of net-zero disturbance power. The disturbance power generation of a blade row is defined in Eq. (3), where primed quantities are unsteady perturbations from the steady, mean flow quantities

$$
P_{\text {blade }}=\iint_{\text {blade }}\left(p^{\prime} V_{x}^{\prime}+\bar{V}_{x}\left(\frac{\left(p^{\prime}\right)^{2}}{2 \bar{\rho} \bar{a}^{2}}+\frac{\bar{\rho}\left(V^{\prime}\right)^{2}}{2}\right)\right) d A
$$

The first term represents the rate at which disturbance-pressure work is performed by the blade. The second and third terms represent the rate of change of the internal and kinetic energy, respectively, of the prestall waves. A compressible dynamic model would be required to compute the disturbance power generation but this was beyond the scope of this work. Instead, data from the mean line model were used to estimate the disturbance power generation. To compute a speed line, the full mean line model was evaluated for a variety of mass flows at constant speed, producing the full flow field at a number of mass flows along the speed line. To estimate the disturbance power generation at a given operating point with mass flow $\dot{m}_{1}$ on the speed line, the flow field of the next operating point along the speed line, with mass flow $\dot{m}_{2}$, was cast as perturbation, i.e., $\dot{m}_{2}=\dot{m}_{1}+\dot{m}^{\prime}$. The flow field at $\dot{m}_{2}$ was utilized to compute the perturbation quantities shown in Eq. (3), e.g., $V^{\prime}=V_{2}-V_{1}$. In the absence of a fully compressible dynamic compressor model, this method made the best possible use of the available information from the quasi-steady model to estimate the disturbance power generation.

The disturbance power approach for modal-type stall inception is relevant in multistage compressors where operation on the positively sloped side of the pressure-rise characteristic may be possible due to a single strong stage stabilizing the system [15]. It is of even greater importance in this study as the increased losses and flow angle deviation due to heat addition, and the associated stage mismatching, alter the slope of the characteristic and promote modal-type stall inception.

\section{Effects of Heat Transfer on Compressor Performance}

A challenge when considering nonadiabatic transients is the unsteady nature of the heat transfer with the main gas path. The stage matching is dependent on the heat transfer distribution, and thus, the entire compressor map, the speed lines, stall line, and operating point are all functions of time. The compressor map is altered throughout a nonadiabatic transient, differing from the adiabatic case.

The general effects of heat transfer on the compressor speed lines are demonstrated generically for a single speed line in Fig. 4, with the adiabatic compressor map shown in black. For the case of heat addition to the gas path fluid $\left(q^{*}>0\right)$, the speed lines shift to lower corrected flows due to mismatching. The speed lines also shift to lower pressure ratios due to the increased loss and reduction in flow turning from increased deviation. The operating point moves to a higher pressure ratio and the stalling pressure ratio is reduced, resulting in stall margin loss. The slope of the speed line decreases, primarily due to mismatching, promoting modal-type stall inception and reducing the stable operating range. For heat extraction $\left(q^{*}<0\right)$, the opposite effects occur; the flow capacity and the stalling pressure ratio increase, the operating point moves to a lower pressure ratio, and the speed line grows steeper.

At each instant during the transient, a distinct heat transfer distribution occurs and the compressor rematches accordingly, 


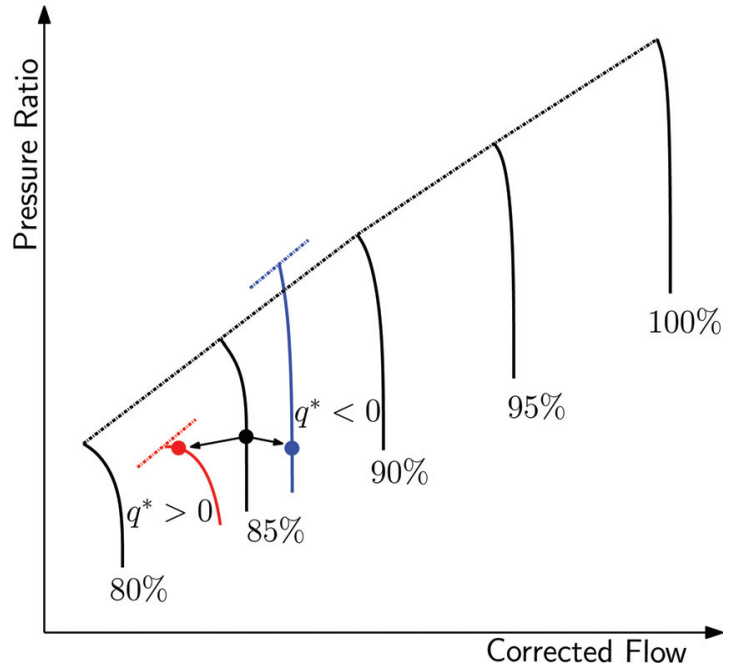

Fig. 4 Generic representation of the effects of heat transfer on a compressor speed line. Heat addition to the gas path fluid reduces flow capacity, stalling pressure ratio, and speed line slope.

producing a unique speed line and operating point. The time dependence of the speed lines is shown generically in Fig. 5 for three distinct times during a re-acceleration transient: heat addition at $\tau=0.0$, zero net heat transfer at $\tau=0.5$, and heat extraction at $\tau=0.75$. $^{5}$ The effect of unsteady heat transfer on the transient operating line is also demonstrated in Fig. 5. During periods of heat addition, the transient operating line upmatches, moving to higher pressure ratios relative to the adiabatic case. The colors are used to represent the heat transfer magnitude at the time that speed was reached, with dark red representing maximum heat addition and dark blue representing maximum heat extraction. As before, the adiabatic compressor map and the transient operating line are shown in black.

To represent the constantly changing compressor map in a single representation, we define a "composite compressor map." The composite compressor map is an ensemble of speed lines, each realized with the heat transfer distribution at the time the speed was reached during the transient. It can be thought of as a collection of nonadiabatic speed lines for various instants in time throughout the transient. The stall line in the composite compressor map is defined by interpolating between the stall points of the nonadiabatic speed lines. The transient stall margin can be computed by overlaying the transient operating line on the composite compressor map, as is done in Fig. 6. The adiabatic compressor map and operating line, in black, serve as a basis of comparison and highlight the effects of heat transfer.

Figure 7 shows the composite compressor map as computed by the mean line model for the re-acceleration portion of the Bodie transient from Fig. 1. For clarity, the entirety of the nonadiabatic transient is shown in red, unlike in Fig. 6, even though the compressor experiences heat extraction at high speeds. The transient operating line shows greater excursion at low speed, when high levels of heat addition occur, but more significantly the stalling pressure ratio is reduced by as much as $11 \%$. These two factors produce a maximum net reduction in stall margin by 8.0 points as shown in Fig. 8, which compares the computed stall margin of the nonadiabatic and adiabatic cases as a function of corrected speed throughout the transient. The computed stall margin is also shown when heat transfer effects on flow angle deviation are removed $(\zeta=0)$ and any stall margin loss is due entirely to compressor rematching. Of the maximum 8.0 points of stall margin loss, 4.6

\footnotetext{
${ }^{5}$ The times given here are generic and are not intended to reflect times shown in Fig. 3 .
}
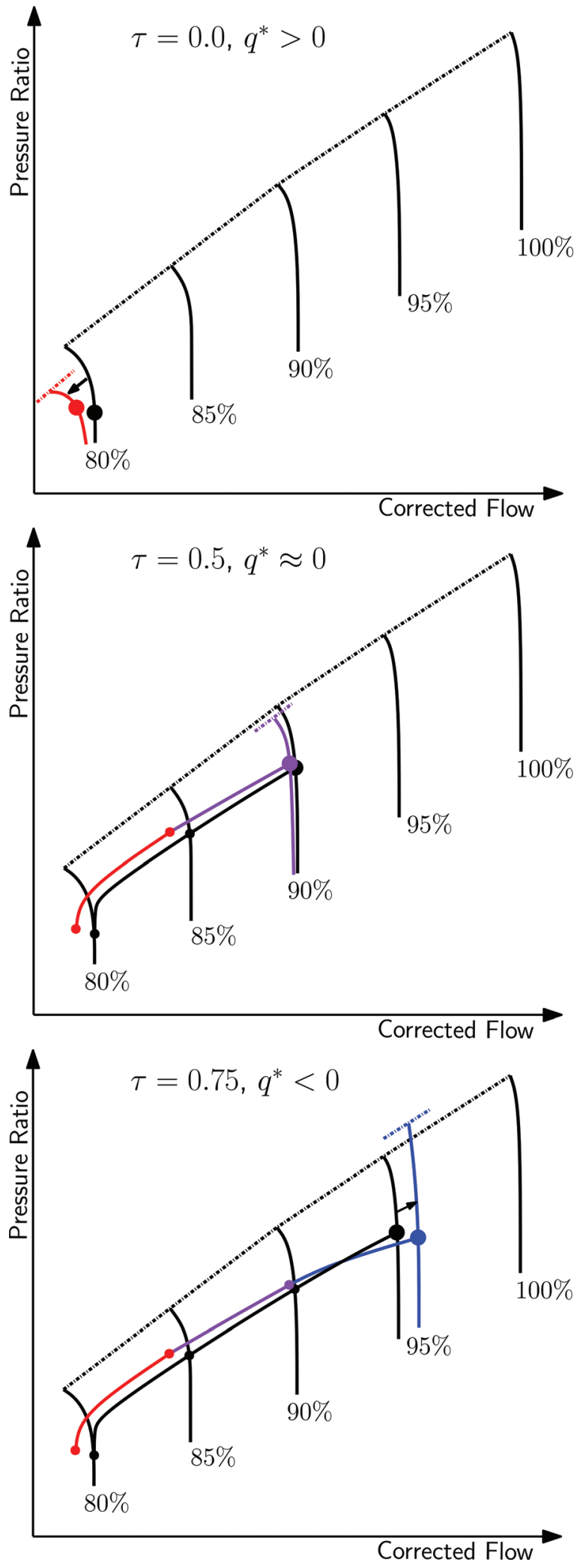

Fig. 5 Generic representation of time-dependent speed lines due to unsteady heat transfer

(58\%) are attributable to rematching, although this percentage changes at higher speeds with less stall margin loss. Above $91 \%$ speed, the nonadiabatic cases have greater stall margin than the adiabatic case. This corresponds to the moment during the transient in which heat is no longer added to the main gas path but extracted, occurring at $\tau=1.25$ in Fig. 3 . 


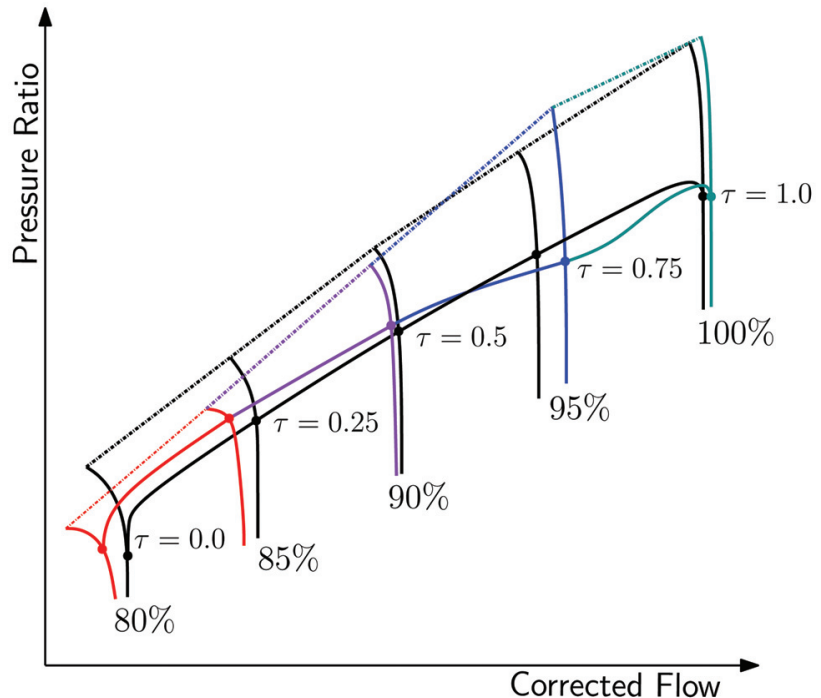

Fig. 6 Schematic example of a composite compressor map used to represent the unsteady nature of speed lines and stall line during a transient with heat transfer

The predicted 8.0 point reduction in stall margin is comparable to the 12.2 point reduction estimated by Maccallum and Grant [3]. Whereas $60 \%$ of the maximum stall margin loss was attributed to deviation effects in Ref. [3], only $42 \%$ of the total stall margin loss is due to deviation effects in the present study (Maccallum et al. only considered the point of maximum stall margin loss). This difference is attributable to the large differences in architecture of the test compressor. Maccallum et al. examined a 12 stage compressor of pressure ratio five, while the current study is of an eight stage, high-speed compressor with a pressure ratio several times higher. The importance of stage matching increases with rising overall pressure ratios and falling stage counts.

\section{Mechanism of Stall Margin Loss Due to Heat Transfer}

Given that heat addition tends to reduce the slope of the speed lines, it is expected that heat transfer influences the stall inception mechanism. Table 1 compares the net heat transfer rate $q_{\text {comp,net }}^{*}$

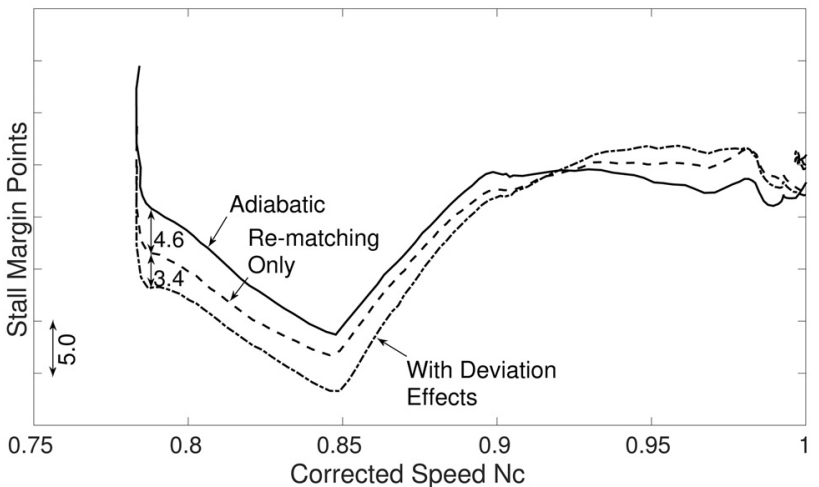

Fig. 8 Stall margin throughout the re-acceleration transient with a maximum of 8.0 points of stall margin loss

Table 1 Comparison of net heat transfer rate and type of stall inception throughout re-acceleration transient. Heat addition promotes modal-type stall inception.

\begin{tabular}{lccc}
\hline \hline Time, $\tau$ & Speed $(\%)$ & Heat transfer, $q_{\text {comp,net }}^{*}$ & Stall inception \\
\hline 0.0 & 78 & 0.091 & Modes \\
0.5 & 83 & 0.052 & Modes \\
0.9 & 87.5 & 0.025 & Modes \\
1.2 & 90 & 0.010 & Modes \\
1.5 & 95 & -0.026 & Modes \\
1.7 & 97.5 & -0.037 & Spikes \\
2.0 & 99 & -0.031 & Spikes \\
\hline
\end{tabular}

and the path into instability (either spikes or modal waves) for several different times in the transient. The stall inception type was determined by the stall criteria: if the diffusion factor criterion was met first, it was considered spike-type, and if the disturbance power criterion was first met, it was considered modal-type. The stall inception was modal-type for all the time instants shown with heat addition and spike-type for nearly all times with heat extraction, supporting the hypothesis that heat addition promotes modal-type stall inception. Further evidence is found in Fig. 9 which demonstrates the change in disturbance power generation

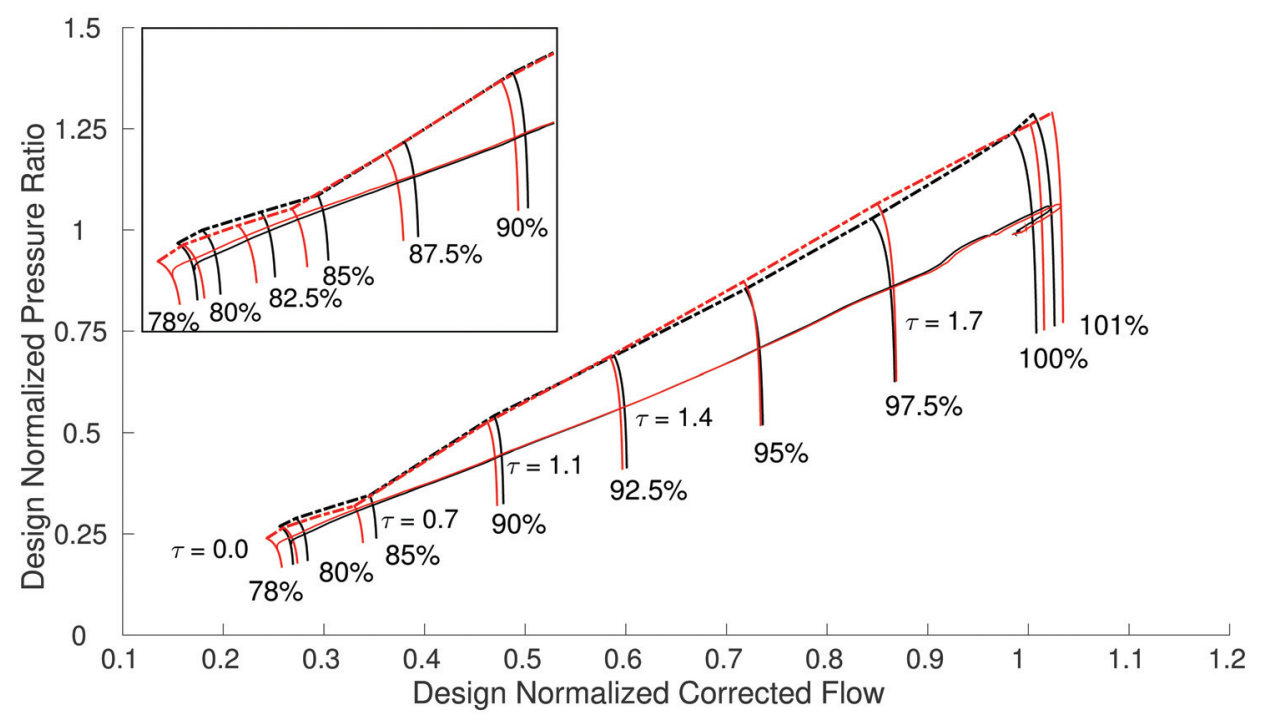

Fig. 7 Computed composite compressor map with heat transfer. Heat transfer produces a larger shift in the stall line than the transient operating line. 


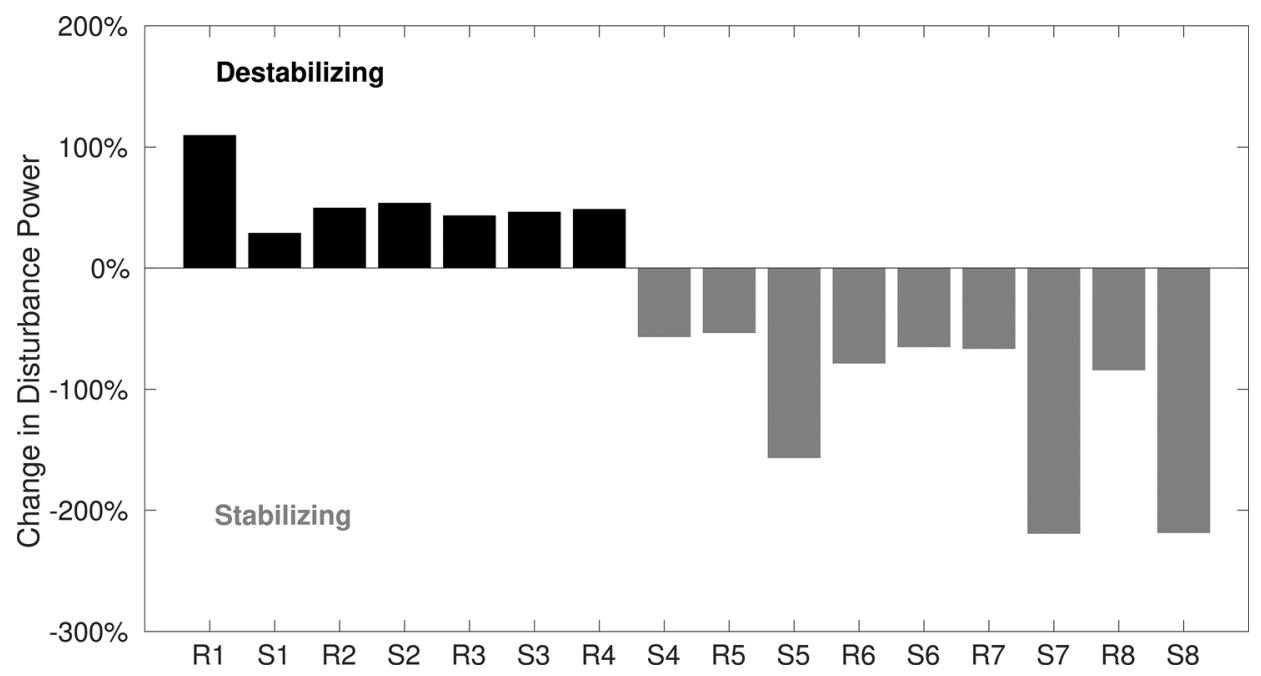

Fig. 9 Median percent change in blade row disturbance power generation due to heat addition. Front stages produce greater disturbance power and destabilize the compressor.

for each blade row across all speeds with heat addition. With heat addition, the front blade rows generate more disturbance power and provide less damping, while the rear blade rows generate less disturbance power and provide more damping. The implication is that compressors operating near the peak of their pressure rise characteristic are likely to suffer greater stall margin loss due to transient heat transfer as heat addition reduces the slope of the characteristic, resulting in operation on the unstable, positively sloped side.

In order to characterize the mechanism for the increased disturbance power generation of the front stages, the compressor was split into three blocks and three calculations were performed in which heat transfer was isolated to one of the blocks. The total heat transfer in each calculation was one-third of the total heat transfer at $\tau=0.0$, the maximum throughout the transient. The heat transfer was evenly divided among the blade rows in the block and the compressor exit corrected flow was held constant, as required for compressor-turbine matching.

The axial Mach numbers for each of the heat transfer distributions are given in Figs. 10-12 to illustrate the effects of heat transfer on stage matching. As the exit corrected flow remains fixed, the Mach number reduces in the blade rows upstream of heat addition in order to pass the required physical mass flow. In other words, the heat addition in a block back-pressures the upstream blade rows. To some extent, the blocks are de-coupled as the effects of the heat addition are felt by the blocks upstream, while the downstream blocks largely unaffected by the heat addition. The highly loaded front stages produce greater disturbance power

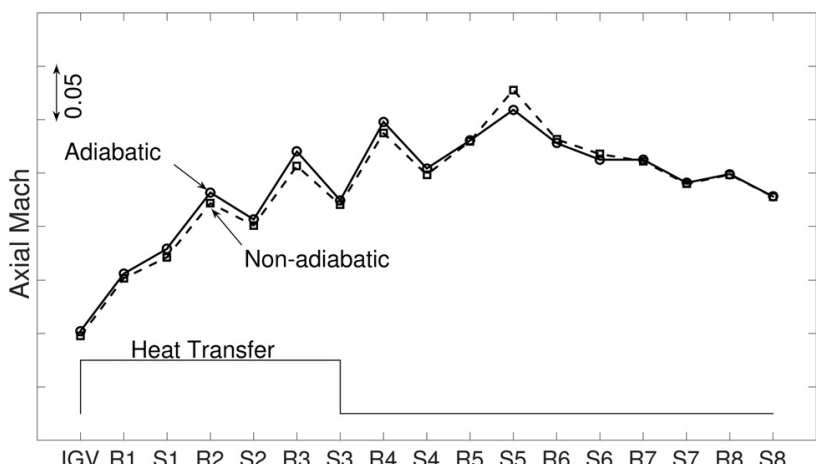

Fig. 10 Axial Mach numbers with uniform heat addition in front block. Heat addition increases front block loading. and the compressor stalls at a lower pressure ratio. Increases in flow angle deviation exacerbate this effect by reducing the turning, and thus, the pressure rise of the stage. Reduced pressure rise through the compressor requires a further decrease in mass flow, and thus Mach number, to achieve the required exit corrected flow for compressor-turbine matching.

The above study serves as a useful diagnostic to characterize how the compressor responds to heat addition at different axial

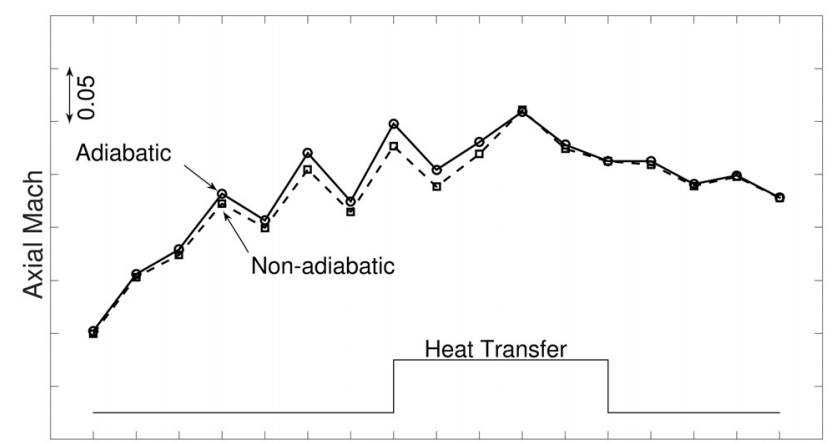

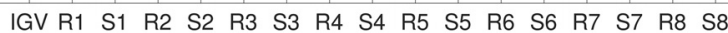

Fig. 11 Axial Mach numbers with uniform heat addition in middle block. Effects of heat addition are contained to front and middle blocks.

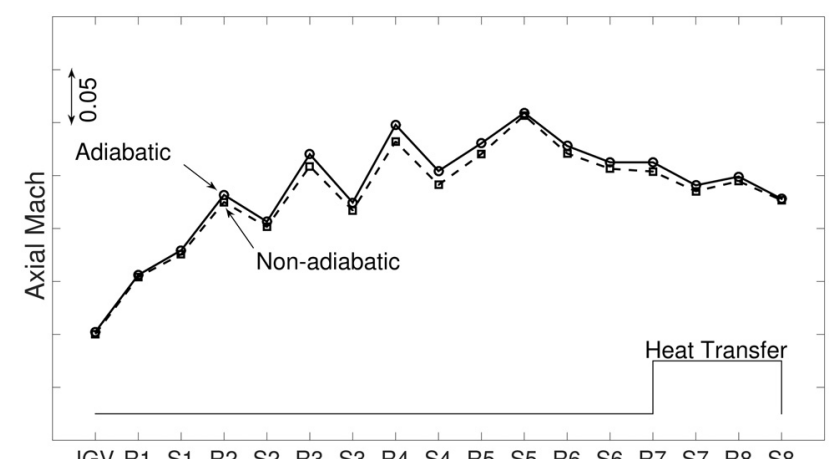

Fig. 12 Axial Mach numbers with uniform heat addition in rear block. Heat addition back-pressures all upstream blade rows. 


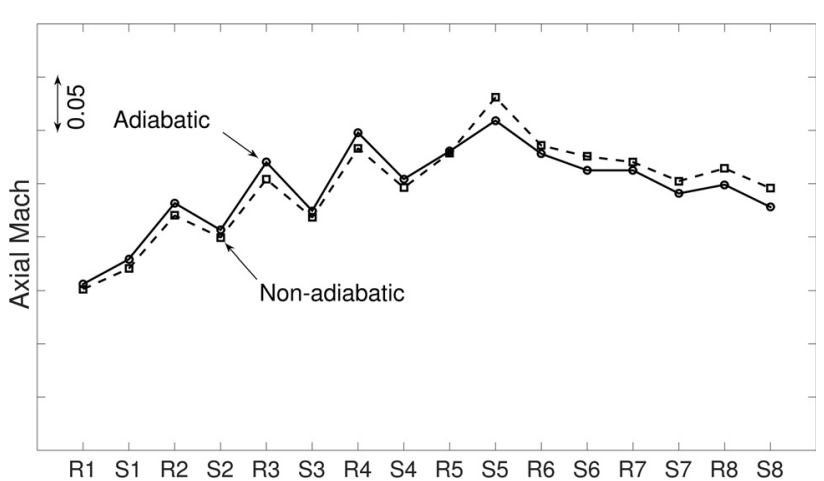

Fig. 13 Axial Mach numbers at the $78 \%$ speed stall point. Heat addition increases loading of front stages.

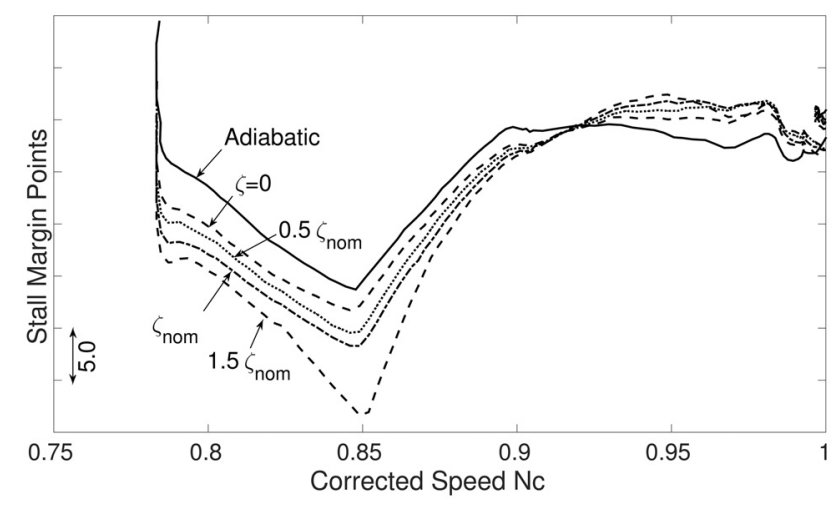

Fig. 14 Sensitivity of stall margin to deviation correlation parameter $\zeta$. Nonlinear dependence at $85 \%$ speed attributed to compressibility effects.

locations. In reality, however, heat is added throughout the machine and all the stages rematch accordingly. The axial Mach numbers for the $78 \%$ speed stall point are given in Fig. 13. Heat addition exacerbates the classic low speed matching problem where the front stages operate near stall and the rear stages windmill (see Ref. [16]). The changes in disturbance power generation seen in Fig. 9 are mirrored in Fig. 13 with the front blade rows operating at higher loading and producing more disturbance power and the rear blade rows operating at lower loading and producing less disturbance power. The mechanism of increased front stage loading and stall implies that compressor designs with highly loaded front stages may be more sensitive to heat transfer and suffer greater transient stall margin loss.

\section{Sensitivity Study}

Transient heat transfer has been shown to produce up to eight points of stall margin loss, with $42 \%$ attributed to deviation effects. Estimates of heat transfer and deviation data, however, often have significant uncertainties, especially in the early design phase. It is therefore useful to characterize the sensitivities of stall margin loss to heat transfer magnitude and the deviation correlation. Several calculations were performed with modified values of the deviation correlation sensitivity $\zeta$ in Eq. (2) and the heat transfer magnitude. Specifically, $\zeta$ was multiplied by factors of 0.5 and 1.5 and the dimensional heat transfer rate $\dot{Q}(\tau)$ for each blade row was multiplied by factors of 0.75 and 1.25 . The stall margin results for these calculations are given in Figs. 14 and 15.

Between $82.5 \%$ and $87.5 \%$ speed, the stall margin loss increases nonlinearly from the nominal case, with an increase of stall margin loss from 5.4 points to 13 points at $85 \%$ speed for

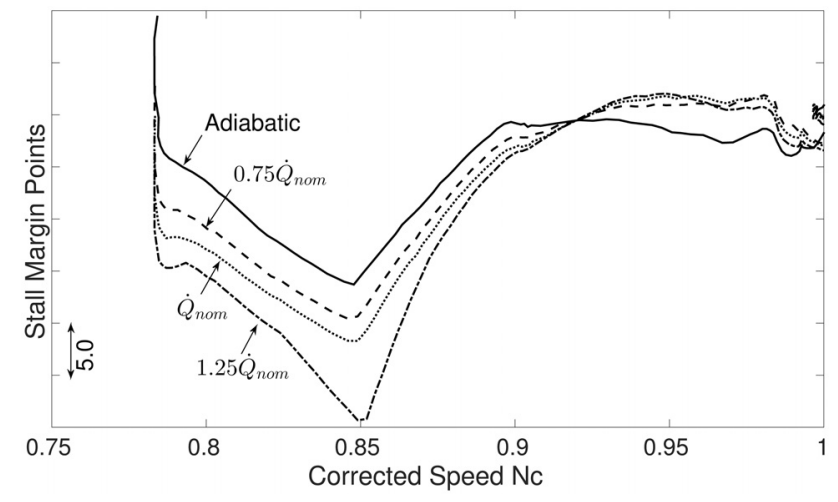

Fig. 15 Sensitivity of stall margin to heat transfer magnitude with the same sensitivity observed at $85 \%$ speed

only a $25 \%$ or $50 \%$ increase in heat transfer rate and deviation, respectively. The $85 \%$ speed line in Figs. 1 and 7 corresponds to the "knee" of the stall line. This knee is the result of the effects of compressibility as the tip and blade relative Mach numbers increase. Heat addition increases blade relative Mach numbers (by as much as $5 \%$ ), promoting compressibility effects, and it is hypothesized that this results in the strong sensitivity observed in Figs. 14 and 15.

Below $82.5 \%$ speed, the stall margin loss is approximately linear with deviation and heat transfer rate. At these speeds, the blade relative Mach numbers are in the low subsonic range and compressibility is less significant. Furthermore, while the net heat transfer rate to the main gas path was as much as $9.5 \%$ of the compressor inlet stagnation enthalpy inflow rate $\left(q_{\text {comp.net }}^{*}=0.095\right)$, the maximum heat addition for any individual blade row was only $0.5 \%$ of the blade row inlet stagnation enthalpy inflow rate $\left(q^{*}=0.005\right)$. As values of $q^{*}$ grow, it is expected that the impact on stall margin loss will become nonlinear at low speed as well.

\section{A New Mean Line Capability Including Heat Transfer Effects}

Current transient heat transfer analysis of compressors in the default NPSS cycle model is limited to a single mass, uniform temperature representation of the compressor. ${ }^{6}$ The user provides the total thermal mass and surface area, specific heat, and an estimated average convective heat transfer coefficient for the entire compressor. In a transient calculation, the solver calculates the convective heat transfer from a weighted average of the compressor inlet and outlet stagnation temperatures, adding the estimated heat transfer to the flow at the compressor exit, and models the change in metal temperature with a first-order lag equation. The standard model does not change the compressor component characteristics and the effects of stage rematching and deviation are not modeled. In this case, the heat transfer simply acts to change the compressor exit corrected flow (through the change in total temperature), which in turn changes the overall matching with the downstream components.

To assess the new capability provided by the nonadiabatic mean line model, a calculation representative of the current capability was performed. The net compressor heat transfer at each instant in time was added to the flow at the exit of stator 8 and all remaining blade rows were adiabatic. The stage matching and deviation throughout the compressor was unchanged from the adiabatic case, with only the exit corrected flow changing due to the heat transfer. The heat addition at the compressor exit back pressures the compressor and drove the transient operating to higher

\footnotetext{
${ }^{6}$ These limitations apply to the default "compressor" module that is provided with the publicly available NPSS distribution.
} 


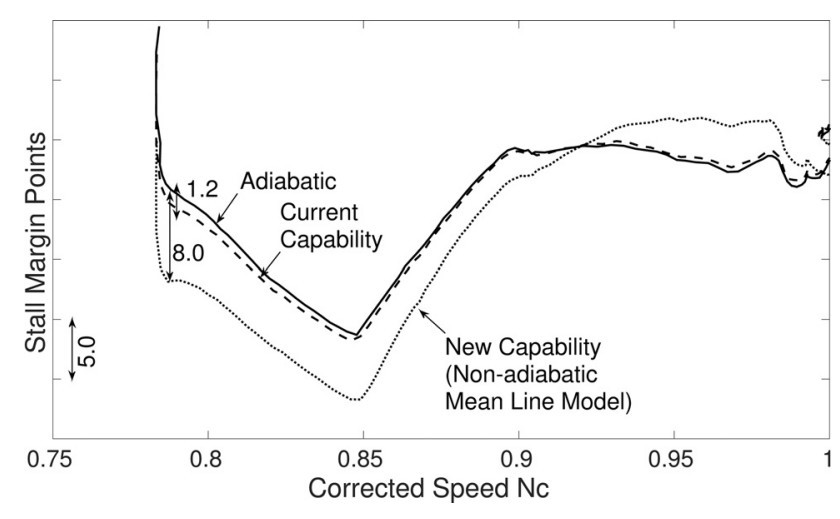

Fig. 16 Stall margin computed with nonadiabatic mean line model and current capability which captures only 1.2 points of stall margin loss

pressure ratios, but as the stage matching was unchanged and the heat addition is small, at most $4 \%$ of that in the combustor, the increase in the operating line pressure ratio was at most $1 \%$ for the same corrected speed (as compared to $4 \%$ with the nonadiabatic mean line model). More importantly, the stall line produced with the current capability is unchanged from the adiabatic case. As shown in Fig. 16, the current capability captures a stall margin loss of only 1.2 points relative to the 8.0 points of the nonadiabatic mean line model, emphasizing the importance of capturing the effects of stage rematching and deviation.

\section{Summary}

A mean line model was extended to capture the effects of heat transfer and used to evaluate the effect of heat transfer on stall margin during the re-acceleration phase of a Bodie transient event. A lumped capacitance model was developed to estimate representative heat transfer to the main gas path on a blade row by blade row level. The maximum heat transfer was $9.5 \%$ of the compressor inlet stagnation enthalpy inflow rate and occurred at the initial point of re-acceleration in the Bodie transient. Heat transfer resulted in a total stall margin loss of 8.0 points, largely due to the reduction in stalling pressure ratio by as much as $11 \%$. Of the 8.0 points, 4.6 points $(58 \%)$ were due to stage rematching effects, with the remaining 3.4 points due to the effects of heat transfer on flow angle deviation. An analysis of the stage rematching revealed that the heat transfer increases the loading in the front blade rows and promoted front stage stall, suggesting that the effect of transient heat transfer may be greater for compressors with highly loaded front stages. Furthermore, it was found that heat addition reduced the slope of the speed lines, increased blade disturbance power generation, and promoted modal-type stall inception. This suggests that compressors operating near the peak of their pressure rise characteristic are likely to suffer greater stall margin loss due to transient heat transfer.

A sensitivity study analysis indicated the dependence of stall margin loss on heat transfer magnitude and flow angle deviation is highly nonlinear near the knee of the stall line, showing an increase in stall margin loss from 5.4 points to 13 points with only an increase in $25 \%$ and $50 \%$ of these quantities, respectively. This nonlinearity is attributed to compressibility effects, as heat addition increases flow Mach numbers. At lower speeds, where the effects of compressibility are less significant, the stall margin loss is approximately linear, though it is thought the dependence becomes nonlinear as the magnitude of $q^{*}$ grow.

Calculations representative of the current NPSS modeling capability for transient heat transfer effects, which does not capture stage rematching or deviation effects, indicate that only 1.2 points of the total 8.0 points of stall margin loss is captured by the current capability. This underscores the importance of capturing stage rematching and deviation effects. Furthermore, the low computational cost of the nonadiabatic mean line model highlights the opportunities to address potential stability issues due to transient heat transfer early in the compressor design process.

\section{Acknowledgment}

The authors would like to thank Gavin Hendricks for his continual guidance and support and Brian Schuler for his assistance in developing the mean line model. Further thanks go to Scott Jones at NASA Glenn Research Center for providing OTAC and to the reviewers whose comments have helped improve this paper. The authors are also indebted to Professor Nick Cumpsty for his insightful comments and discussions. This work is funded by Pratt \& Whitney, which is gratefully acknowledged.

\section{Nomenclature}

$$
\begin{aligned}
& a=\text { speed of sound } \\
& A=\text { area } \\
& h_{t, i}=\text { blade row inlet stagnation enthalpy } \\
& h_{t, \mathrm{comp}}=\text { compressor inlet stagnation enthalpy } \\
& L_{\text {comp }}=\text { compressor length } \\
& \dot{m}=\text { mass flow } \\
& M_{\text {rel }, i}=\text { blade row inlet rotating-frame Mach number } \\
& \mathrm{Nc}=\text { corrected speed } \\
& p=\text { static pressure } \\
& p_{t}=\text { stagnation pressure } \\
& P_{\text {blade }}=\text { blade row disturbance power } \\
& \mathrm{PR}=\text { pressure ratio } \\
& \dot{Q}=\text { dimensional heat transfer rate } \\
& q^{*}=\text { blade inlet normalized heat transfer rate, } q^{*}=\frac{\dot{Q}}{\dot{m} h_{t i}} \\
& q_{\mathrm{comp}}^{*}=\text { compressor inlet normalized heat transfer rate, } \\
& q_{\text {comp }}^{*}=\frac{\dot{Q}}{\dot{m} h_{\text {t.comp }}} \\
& q_{\mathrm{comp}, \text { net }}^{*}=\text { net heat transfer rate, } q_{\mathrm{comp}, \text { net }}^{*}=\sum_{\text {blades }} q_{\mathrm{comp}}^{*} \\
& t=\text { time } \\
& t_{\mathrm{acc}}=\text { rotor acceleration time constant, } N c \sim 1-e^{-\frac{t}{t_{\mathrm{acc}}}} \\
& V=\text { flow velocity } \\
& V_{x}=\text { flow axial velocity } \\
& \beta=\text { reduced frequency, } \beta=\frac{L_{\mathrm{comp}} / V_{x}}{t_{\mathrm{acc}}} \\
& \gamma=\text { ratio of specific heats } \\
& \delta=\text { blade flow angle deviation } \\
& \zeta=\text { deviation correlation parameter } \\
& \rho=\text { density } \\
& \tau=\text { nondimensional time, } \tau=\frac{t}{t_{\mathrm{acc}}}
\end{aligned}
$$

\section{References}

[1] Schulte, H., Schmidt, K., Weckend, A., and Staudacher, S., 2008, "Multi-Stage Compressor Model for Transient Performance Simulations," ASME Paper No. GT2008-51159.

[2] Schölce, M., Merkler, R., Schulte, H., and Schmidt, K., 2005, "Simulation of Clearance Changes and Mechanical Stresses in Transient Gas Turbine Operation by a Matrix Method," AIAA Paper No. 2005-4022.

[3] Maccallum, N., and Grant, A., 1978, "The Effect of Boundary Layer Changes Due to Transient Heat Transfer on the Performance of an Axial-Flow Air Compressor," Society of Automotive Engineers, New York, Technical Report No. 770284.

[4] Crawford, R., and Burwell, A., 1985, "Quantitative Evaluation of Transient Heat Transfer on Axial Flow Compressor Stability," AIAA Paper No. 19851352 .

[5] Lou, F., Fabian, J., and Key, N., 2017, "Stall Inception in a High-Speed Centrifugal Compressor During Speed Transients," ASME J. Turbomach., 139(12), p. 121004

[6] Kiss, A., 2015, "Two Investigations of Compressor Stability: Spike Stall Inception and Transient Heat Transfer Effects," Master's thesis, Massachusetts Institute of Technology, Cambridge, MA

[7] Jones, S., 2014, "Development of an Object-Oriented Turbomachinery Analysis Code Within the NPSS Framework," National Aeronautics and Space Administration, Hanover, MD, Technical Report No. TM-2014216621. 
[8] Jones, S., 2015, "Design of an Object-Oriented Turbomachinery Analysis Code: Initial Results," International Symposium on Air-Breathing Engines, Phoenix, AZ, Oct. 25-30, Report No. ISABE-2015-20015.

[9] Shah, P., 2007, "Novel Turbomachinery Concepts for Highly Integrated Airframe/Propulsion Systems," Ph.D. thesis, Massachusetts Institute of Technology, Cambridge, MA.

[10] Farthing, P., Long, C., Owen, J., and Pincombe, J., 1992, "Rotating Cavity With Axial Throughflow of Cooling Air: Heat Transfer," ASME J. Turbomach., 114(1), pp. 229-236.

[11] Camp, T., and Day, I., 1998, "A Study of Spike and Modal Stall Phenomena in a Low-Speed Axial Compressor,” ASME J. Turbomach., 120(3), pp. 393-401.
[12] Pullan, G., Young, A., Day, I., Greitzer, E., and Spakovszky, Z., 2014, "Origins and Structure of Spike-Type Rotating Stall,” ASME J. Turbomach., 137(5), p. 051007.

[13] Lieblein, S., 1959, "Loss and Stall Analysis of Compressor Cascades," J. Basic Eng., 81, pp. 387-400.

[14] Frechette, L., 1997, "Implications of Stability Modeling for High-Speed Axial Compressor Design," Master's thesis, Massachusetts Institute of Technology, Cambridge, MA.

[15] Longley, J., and Hynes, T., 1990, "Stability of Flow Through Multistage Axial Compressors," ASME J. Turbomach., 112(1), pp. 126-132.

[16] Cumpsty, N. A., 2004, Compressor Aerodynamics, Krieger Publishing Company, Malabar, FL. 